\title{
Analysis of the Defence Responses to Tomato Spotted Wilt Orthotospovirus (TSWV) and Hippeastrum Chlorotic Ringspot Orthotospovirus (HCRV) Infection in Capsicum Annuum Based on Transcriptome
}

\author{
Zhiqiang Jia \\ Yunnan Agricultural University \\ Xue Gao \\ Yunnan Agricultural University \\ YeXu \\ Southern Medical University \\ Hongzheng Tao \\ Yunnan Agricultural University

\section{Baoju Yang} \\ Yunnan Agricultural University \\ Min Gui \\ Yunnan Agricultural University \\ Yating Liu ( $D$ liuyating66@163.com ) \\ Yunnan Agricultural University \\ Yongzhong Li \\ Yunnan Agricultural University
}

\section{Research}

Keywords: Orthotospovirus, Transcriptome, Defense processes

Posted Date: December 18th, 2020

DOI: https://doi.org/10.21203/rs.3.rs-129901/v1

License: (c) (i) This work is licensed under a Creative Commons Attribution 4.0 International License. Read Full License 


\section{Abstract}

Background: Orthotospovirus has a wide range of hosts, widely distributed in southwestern China and have serious harm to crop production. Tomato spotted wilt orthotospovirus (TSWV) and Hippeastrum chlorotic ringspot orthotospovirus (HCRV) are seriously harms the quality of pepper (Capsicum annuum L.). However, the detailed molecular mechanism of pepper disease caused by TSWV and HCRV remains obscure.

Method: Transcriptome analysis (RNA-seq) based on high-throughput sequencing, with TSVV, HCRV and mock-inoculated plants as controls, to investigate and compare the gene expression changes in pepper leaves, and analyze the plants invaded by orthotospoviruses defensive response.

Results: The RNA-Seq results of pepper 1 day after inoculation ( $1 \mathrm{dpi}$ ) showed that the number of differentially expressed genes(DEG) after HCRV infection was greater than that after TSWV infection. Gene Ontology enrichment and KEGG pathway analyses were performed on the two viruses, and the KEGG results showed that DEG were mainly enriched in plant-pathogen interactions, plant hormone signal transduction, and defence processes.

Conclusion: The conclusion of this study is that after orthotospovirus infects pepper, the DEG changes in the processes of plant-pathogen interaction, plant hormone and phenylpropanoid synthesis. In addition, transcription factors such as WRKY and MYB changed significantly. These factors comprehensively affect the plant's defence response and ultimately enhance the plant's resistance to viruses. Findings of present study will significantly help enhance our understanding of the complicated defense process of plant responses to orthotospoviruses infection.

\section{Introduction}

Pepper (Capsicum annuum L.) is a favourite vegetable rich in vitamin C, which is good for human health. According to factors such as the degree of damage and host range, 68 kinds of viruses in the world infect peppers[1]. Tomato spotted wilt orthotospovirus (TSWV) and Hippeastrum chlorotic ringspot

orthotospovirus (HCRV) are orthotospoviruses that are transmitted by thrips (Thysanoptera) and are able to infect over 900 kinds of plant species within more than 90 families [2, 3]. TSWV, Impatiens necrotic spot orthotospovirus (INSV)[4], Groundnut ringspot orthotospovirus (GRSV)[5], Watermelon silver mottle orthotospovirus (WSMoV), Tomato chlorotic spot orthotospovirus (TCSV)[6], Groundnut bud necrosis orthotospovirus (GBNV)[5], Pepper necrotic spot orthotospovirus (PNSV), Pepper chlorotic spot orthotospovirus (PCSV), Capsicum chlorosis orthotospovirus (CaCV)[7], Alstroemeria necrotic streak orthotospovirus (ANSV)[8], and Chilli yellow ringspot orthotospovirus (CYRSV)[9] can infect peppers, causing pepper leaf chlorosis, necrosis, concentric rings, necrotic spots, and pepper fruit deformity, which seriously affect yield and quality[10].

High-throughput technology has been widely used in the study of orthotospoviruses and plant interactions. Microarray and high-throughput sequencing technologies expressing sequence tags were 
used to study the molecular responses of INSV and TSWV host plants. The results showed that INSVinfected tobacco (Nicotiana benthamiana) involved plant defence after INSV infection compared with the control, with upregulation of genes involved in metabolic processes, such as signal transduction and transcription, and downregulation of genes involved in histone expression[11]. TSWV infection also resulted in the upregulation of ethylene-mediated signal transduction pathways and chitin response genes in Dendranthema morifolium (Ramat.) Tzvelev and was involved in the downregulation of genes in DNA metabolism, such as DNA replication, histone modification and cytokinesis[12]. After TZSV infects pepper (Capsicum annum L., 'Zunla-1') and $N$. benthamiana, the accumulation of jasmonic acid (JA) increases, and salicylic acid (SA) decreases. It was also proven that JA and SA inhibited the fitness of western flower thrips (Frankliniella occidentalis), and 2102 differentially expressed genes (DEG) were identified after tobacco infection. These DEG are mainly related to biological functions such as metabolic processes, redox processes, and protein kinase activity. KEGG pathway analysis shows that the pathogenesis of TZSV may affect the primary and secondary metabolism of tobacco and the interactions between plants and pathogens[13, 14]. However, there have been few reports on the study of the two viruses of Orthotospovirus on the same plant. Therefore, the differences in hormone signal transduction, plant defence response and secondary metabolism between the two orthotospoviruses after infection of the same plant are the focus of this study.

Orthotospoviruses are very harmful to crops, but there are still many challenges in effective prevention and control. Disease resistance breeding, phytosanitation, cultivation control strategies, and the use of pesticides and nonbiological or biological inducers to enhance plant resistance to pathogens are of great significance to the prevention and control of viruses $[15,16]$. The basis of disease resistance breeding is to analyse the changes in metabolic pathways and differential genes in the process of the plant defence response after orthotospoviruses infect plants to conduct in-depth research on the disease resistance characteristics of host plants. The near-isogenic $S w$-7line and its susceptible recurrent parent material were used for comparative transcriptome and gene expression analyses to identify processes such as host resistance and RNA silencing/antiviral defence as well as key transcription and translation regulatory factor networks of 1244 differential genes and to verify that the PR- 5 gene is involved in the resistance process of $S w-7$ to TSWV[17].

Through a dynamic transcriptomics study after TSWV infects Arabidopsis thaliana, the results showed that the plant immune defence and protein degradation processes are enhanced after TSWV infects the plant, and photosynthesis and cell wall metabolism are weakened[18]. In addition, plant transcription factors play important roles in plant growth and biotic and abiotic stresses. WRKY proteins are a superfamily of transcription factors that participate in many plant processes, including defence responses to biotic and abiotic stresses[19-25]. Therefore, this study used high-throughput sequencing technology to study the defence responses of two orthotospoviruses after infecting peppers and compared them. A comparative transcriptomics analysis method was used to identify the host plant defence-related metabolic processes and the changes in differential genes and transcription factors. The prevention and control of orthotospoviruses provide a reference. 


\section{Methods}

\section{Pepper cultivation and virus preparation}

Tomato spotted wilt orthotospovirus (TSWV, GC-1 isolate) and Hippeastrum chlorotic ringspot orthotospovirus (HCRV, HLS1-2 isolate) were isolated from Yunnan Province, China, and stored in our laboratory. Their entire genomes have been sequenced. When in use, the virus was removed from the refrigerator and inoculated by friction on $N$. benthamiana to activate the virus for subsequent experiments.

The experimental material Capsicum annuum (Solanaceae) used in this study was from Hunan Xiangyan Seed Industry Co., Ltd(Changsha, Hunan province, China). TSWV can systematically infect Xiangyan 11, but HCRV cannot infect Xiangyan 11. The pepper seeds were planted in a plastic pot (10 $\mathrm{cm} \times 10 \mathrm{~cm} \times 10 \mathrm{~cm}$ ) with a mixture of soil and humus, and the plants were grown in a greenhouse at $25 \pm 2{ }^{\circ} \mathrm{C}$, with a constant relative humidity of $65 \% \pm 5 \%$ and a photoperiod of $16: 8$ (light: dark). The plants were watered twice a week until they grew to the 4-leaf stage, HCRV and TSWV activated viruses were used for mechanical friction inoculation. The control group was treated with inoculation buffer and placed in a greenhouse under the same conditions for growth. After rubbing inoculation with the two viruses, the top three leaf samples were collected (3 biological replicates), frozen in liquid nitrogen immediately, and stored in a $-80^{\circ} \mathrm{C}$ freezer before being prepared for RNA-Seq. Each sample consisted of leaves of 10 plants. The samples were named NC (Xiangyan 11 healthy plants), CK (Xiangyan 11 control group), $\mathrm{H}$ (Xiangyan 11 treatment group inoculated with HCRV virus) and $\mathrm{T}$ (Xiangyan 11 treatment group inoculated with TSWV virus). There were 3 biological replicates in each group and a total of 12 pepper samples (BioSample accessions: PRJNA665356).

\section{RNA extraction and qRT-PCR experiment}

The experimental process of extracting total RNA from 12 pepper leaf samples by the TRIzol method was performed according to the TianGen Biotech manual (Tiangen Biochemical Technology (Beijing) Co., Ltd., DP421).

To determine the time of sample collection, we selected plant leaves with similar plant symptomatic characteristics and growth status in 4 periods $(1,2,3$, and $7 \mathrm{dpi})$ for qRT-PCR experiments. Using the $\mathrm{N}$ gene sequences of HCRV (Accession number: JX833564) and TSWV (Accession number: JN664252) as the reference sequences, Beacon Designer 7.9 (Premier Biosoft International, Palo Alto, CA) was used to design the primers in the qRT-PCR experiment (Table S5), the internal reference gene was UBI3 (Accession number: AY486137.1)[26], the experimental samples were the inoculation samples and CK in 4 periods, and 3 biological replicates were performed for the samples in each period. qRT-PCR was carried out on a qTOWER 2.2 system (Analytik Jena, Jena, Germany) with TB Green Premix Ex Taq II (Takara Biomedical Technology (Beijing) Co., Ltd.). The $2^{-\Delta \Delta C T}$ method was used to calculate gene expression[27]. We analysed the accumulation of virus genes in the four periods and finally selected the leaves of resistant and susceptible pepper varieties from a specific period as the follow-up experimental materials. 


\section{Transcriptome assembly and differentially expressed genes (DEG) analysis}

To ensure data quality, it is necessary to perform quality control and filtering on sequencing data before information analysis. We further rigorously filtered the clean reads obtained through preliminary filtering after sequencing to obtain high-quality clean reads for subsequent information analysis.

The read comparison tool Bowtie2 (2.2.8) was used to compare high-quality clean reads to the ribosomal RNA of the species (mismatch number: 0), remove the reads of the aligned ribosomal RNA, and use the retained data for subsequent analysis. The comparison software TopHat2 (2.1.1) was used to filter out the reads of ribosomal RNA and to compare them to the pepper reference genome (Capsicum Annuum.v.2.0, CM334, Accession number: AYRZ01000000). The known and new mRNAs identified and predicted for each sample were statistically summarized. HTSeq[28] was used with a joint model to calculate the FPKM value (fragment kilobase of exon model per million mapped reads) to obtain the gene expression level[29].

edgeR software was used to analyse differences in mRNA expression between groups, and FDR and log2FC were used to screen differential transcripts. The screening conditions were FDR $<0.05$ and $|\log 2 \mathrm{FC}|>1$. After obtaining the differentially expressed transcripts, GO and KEGG analyses were performed on the differentially expressed transcripts, and Gene Ontology (GO) enrichment analysis was performed for DEG based on the GOenq (1.10.0) and topGO (2.10.0) R packages[30]. KOBAS software (Beijing, China) was used to detect the DEG in the KEGG pathways[31]. Both annotation analyses used expressed genes $(F P K M \geq 1)$ as background and corrected $p \leq 0.05$.

\section{Transcription factor analysis}

The known plant transcription factors found in the PInTFDB database (http://plntfdb.bio.unipotsdam.de/v3.0/) were used to identify transcription factor (TF) families based on annotations[32].

\section{Quantitative reverse-transcription PCR}

To verify the expression of differential genes, the RNA previously extracted was used for quantitative reverse-transcription PCR (qRT-PCR) experiments, and the $2^{-\triangle \Delta C T}$ method was used to calculate the expression levels of genes[27].

Beacon Designer 7.9 (Premier Biosoft International, Palo Alto, CA) was used to design primers for qRTPCR experiments (Supplemental Table S1). The instrument used for fluorescence quantification was a qTOWER 2.2 fluorescence quantitative PCR system (Analytik Jena, Jena, Germany).

SPSS 26.0 (SPSS Inc., Illinois, USA) was used to perform one-way analysis of variance (ANOVA) on the significant difference between means of the qRT-PCR results. Duncan's test was used, and the significance level was set to $p<0.05$.

\section{Results}




\section{Symptoms and qRT-PCR experimental results after virus inoculation}

After Xiangyan 11 was inoculated with HCRV and TSWV, the trends of the two viruses in pepper plants were inconsistent. The maximum accumulation of viruses was reached during the $1 \mathrm{dpi}$ period. At $0-1$ dpi, HCRV and TSWV both showed increasing trends.

During the period of 1-2 dpi, the accumulations of HCRV and TSWV gradually decreased; thus, $1 \mathrm{dpi}$ was the time point for the maximum accumulation of the two viruses. During the time period of 3-7 dpi, the accumulation of HCRV and TSWV gradually increased. Finally, we chose $1 \mathrm{dpi}$ samples and sent them to Gene Denovo Biotechnology Co., Ltd. (Guangzhou, China) for high-throughput sequencing (Fig. 1).

\section{Transcriptome sequencing results}

To obtain the differences in gene expression of Xiangyan 11 inoculated with HCRV and TSWV viruses, we sequenced the leaves of Xiangyan 11 inoculated with the 2 viruses at $1 \mathrm{dpi}$ on an Illumina HiSeq ${ }^{\mathrm{TM}} 2500$ platform and constructed libraries with the sequencing data. In total, 12 CDNA libraries were prepared using poly(A) enrichment from 3 replicates of 4 treatments consisting of samples (NC1, NC2, NC3, CK1, $\mathrm{CK} 2, \mathrm{CK} 3, \mathrm{~T} 1, \mathrm{~T} 2, \mathrm{~T} 3$ and $\mathrm{H} 1, \mathrm{H} 2, \mathrm{H} 3$ ). cDNA libraries underwent quality assessment and cleaning, and each sequencing library obtained more than 69 million clean reads (Supplemental Table S2). The Q20 and Q30 values of all libraries exceeded $98.46 \%$ and $94.76 \%$, respectively, indicating that these data were suitable for further analysis (Table 1). The original data from the $12 \mathrm{cDNA}$ libraries were saved to the SRA database with accession numbers SRR12726982- SRR12726994. 
Table 1

Quality assessment of the cDNA libraries

\begin{tabular}{|lllllll|}
\hline Samplet & Raw Reads & Clean Reads & Clean Bases & Q20(\%) & Q30(\%) & GC(\%) \\
\hline NC1 & 87126070 & 85822070 & $12.77 \mathrm{G}$ & 98.54 & 94.97 & 41.84 \\
\hline NC2 & 71022684 & 69909718 & $10.41 \mathrm{G}$ & 98.46 & 94.76 & 41.91 \\
\hline NC3 & 74588286 & 73522478 & $10.95 \mathrm{G}$ & 98.57 & 95.04 & 41.87 \\
\hline CK1 & 78260828 & 77222310 & $11.51 \mathrm{G}$ & 98.86 & 95.74 & 41.78 \\
\hline CK2 & 80078622 & 78869070 & $11.74 \mathrm{G}$ & 98.56 & 95.01 & 41.52 \\
\hline CK3 & 93153758 & 91816364 & $13.68 \mathrm{G}$ & 98.70 & 95.28 & 41.84 \\
\hline T1 & 79667856 & 78514498 & $11.68 \mathrm{G}$ & 98.52 & 94.90 & 41.86 \\
\hline T2 & 89897672 & 88601056 & $13.19 \mathrm{G}$ & 98.61 & 95.16 & 41.81 \\
\hline T3 & 90373984 & 89018518 & $13.24 \mathrm{G}$ & 98.53 & 94.96 & 41.83 \\
\hline H1 & 75646856 & 74693856 & $11.12 \mathrm{G}$ & 98.76 & 95.48 & 41.91 \\
\hline H2 & 72681602 & 71675354 & $10.67 \mathrm{G}$ & 98.55 & 95.01 & 41.81 \\
\hline H3 & 73708506 & 72669898 & $10.81 \mathrm{G}$ & 98.55 & 94.99 & 41.69 \\
\hline $\begin{array}{l}\text { † NC indicates healthy plants, CK indicates plants inoculated with buffer, T indicates plants } \\
\text { inoculated with TSWV, and H indicates plants inoculated with HCRV }\end{array}$ & \\
\hline
\end{tabular}

Clean reads were compared to the $C$. annuum reference genome (Capsicum Annuum.v.2.0, Accession number: AYRZ00000000) using Bowtie2 (2.2.8) and Tophat2 (2.1.1) software. The coverage of the comparison to the reference genome exceeded $92.30 \%$, and the unique mapped reads exceeded $72.17 \%$ (Supplemental Table S3).

Cufflinks software was used to reconstruct transcripts based on Tophat2 comparison results and screen the positions of the assembled transcripts on the reference genome for new transcripts. The screening criteria were transcript length $\geq 200 \mathrm{bp}$ and exon number $\geq 1$. The number of known mRNAs obtained through screening exceeded 14,669, more than 34,434 new mRNA transcripts were obtained, and the total number of mRNA transcripts exceeded 49,181 (Supplemental Table S4).

We applied stringent filtering criteria to select highly significant differentially expressed genes (DEG) with at least two-fold differences between the two conditions by setting a cut-off q-value $<0.01$ and log2-fold change $>1$ (Fig. 2A). To better understand the diversity of DEG between each treatment, a Venn diagram was generated (Fig. 2B), and 36 DEG existed in all 3 comparison groups. The results showed that the expression levels of genes changed during HCRV and TSWV infection. 
In this study, four comparison groups (CK-vs-H, CK-vs-T, T-vs-H and NC-vs-CK) were selected for functional annotation analysis. After obtaining the differentially expressed transcripts of each comparison group, GO (Gene Ontology) functional analysis and KEGG pathway (euKaryotic Orthologous Groups) analysis were performed on the DEG.

Compared with the control group (CK), the $\mathrm{H}$ treatment group recorded a total of 2617 DEG belonging to 40 functional groups, and the T treatment group recorded a total of 1587 DEG belonging to 37 functional groups, including biological processes, cell components and molecular functions (Supplemental Figure S1).

To further clarify the response mechanisms of DEG to virus infection of plants, the KEGG database was used to classify and characterize transcriptome DEG into corresponding pathways. Compared with the control group, the $\mathrm{H}$ comparison group (CK-vs-H) had 658 enriched DEG in 115 pathways. Among these pathways, the 13 pathways with the most significant enrichment ( $p$-value $<0.05$ ) were ribosome, protein processing in the endoplasmic reticulum, carbon fixation in photosynthetic organisms, photosynthesisantenna protein, stilbenoid, diarylheptanoid and gingerol biosynthesis, pyruvate metabolism, biosynthesis of amino acids, flavonoid biosynthesis, alanine, aspartate and glutamate metabolism, DNA replication, nitrogen metabolism, microbial metabolism in diverse environments, and arginine biosynthesis. In addition, metabolic pathways related to plant immunity, plant-pathogen interactions, plant hormone signal transduction and other pathways were involved in plant immunity DEG (Fig. 3A). Compared with the control group, the T treatment group (CK-vs-T) exhibited 315 enriched DEG in 103 pathways. Among these pathways, the 14 pathways with the most significant enrichment ( $p$-value $<0.05)$ were DNA replication, phenylpropanoid biosynthesis, stilbenoid, diarylheptanoid and gingerol biosynthesis, biosynthesis of secondary metabolites, flavonoid biosynthesis, spliceosome, a-linolenic acid metabolism, pyruvate metabolism, metabolic pathways, plant circadian rhythm, amino sugar and nucleotide sugar metabolism, riboflavin metabolism, glutathione metabolism, and protein processing in the endoplasmic reticulum (Fig. 3B). In the T-vs-H comparison group, 251 DEG were enriched in 99 pathways. Among these pathways, the five pathways with the most significant enrichment ( $p$-value $<0.05$ ) were the photosynthesis-antenna protein pathway, ribosome, glutathione metabolism, carotenoid biosynthesis, and monoterpenoid biosynthesis (Fig. 3C). In the NC-vs-CK comparison group, 125 DEG were enriched in 81 pathways. The 10 pathways that were significantly enriched ( $p$-value $<0.05)$ were photosynthesisantenna protein pathways, diterpenoid biosynthesis, pyruvate metabolism, amino sugar and nucleotide sugar metabolism, biosynthesis of unsaturated fatty acids, phenylalanine, tyrosine and tryptophan biosynthesis, tryptophan metabolism, a-linolenic acid metabolism, cutin, suberine and wax biosynthesis, and biosynthesis of secondary metabolites (Fig. 3D).

\section{Identification and analysis of plant responses to DEG}

To further analyse the immune responses of the two viruses in infected plants, we focused on the plantpathogen interaction pathways, plant hormone signal transduction and phenylpropanoid synthesis pathways enriched by DEG (Fig. 4, Supplemental Table S5). 
When a plant is infected by a pathogen, it triggers its own defence response and usually uses two defence mechanisms to resist invasion of the pathogen. In total, 18 genes were differentially expressed in the comparison group of $\mathrm{H}$ and control (CK-vs-H), 11 genes were differentially expressed in the comparison group of $\mathrm{T}$ and control (CK-vs-T), and 2 genes were differentially expressed in the comparison group of T-vs-H. Therefore, we found that the defensive response of HCRV to Xiangyan 11 was stronger than that of TSWV.

In the $\mathrm{XY} 11-\mathrm{H}$ sample, we found that most DEG were significantly upregulated (8 upregulated genes, 2 downregulated genes), including calcium-dependent protein kinase (CDPK), heat shock protein (HSP90), and LRR receptor protein kinase (FLS2), with the highest expression at 2.05. Heat shock proteins play a role in the defence process of ETI, and these genes cause a hypersensitive response (HR) in the process of plant resistance to pathogen infection (Fig. 4A).

In the plant hormone signal transduction pathway, it was found that many hormones were upregulated after infection with TSWV and HCRV. HCRV cannot successfully infect Xiangyan 11, but TSWV can successfully infect Xiangyan 11. After HCRV inoculation with Xiangyan 11, the expression levels of TIR1 and SAUR36 genes in the auxin synthesis pathway were significantly downregulated. The upregulated expression of SAPK1 in the abscisic acid (ABA) pathway may affect the synthesis of abscisic acid. In the synthesis of ethylene (ETH), EBF1 downregulates its expression, which relieves the inhibition of the ubiquitinated proteolytic pathway. In the jasmonic acid (JA) synthesis pathway, the two TIFY10A genes in the zinc jasmonic acid domain (JAZ) and the transcription factor MYC2 (bHLH14) are upregulated, and the upregulated expression of JAZ promotes the process of ubiquitinated proteolysis. The upregulated expression of JAZ and MYC2 is conducive to the synthesis of JA and the defence response of plants. The key genes histidine kinase 2 (AHK2) and B-ARR (ARR12) in the cytokinine synthesis pathway (CTK) are both upregulated, and the expression of A-ARR (ARR9) is downregulated. Since the A-ARR gene inhibits the expression of the B-ARR gene, the upregulated expression of the abovementioned genes ultimately increases the accumulation of CTK (Fig. 4B).

The secondary metabolism of plants plays an important role in the defence response of plants, and the synthetic pathway of phenylpropanoids is a common mechanism. The final product of phenylpropanoid biosynthesis is lignin. The accumulation of lignin on the cell wall forms a physical barrier to pathogenic bacteria. In the phenylpropanoid biosynthesis pathway, the expression levels of caffeic acid methyltransferase (COMT), anti-cinnamic acid 4-monooxygenase (CYP73A), peroxidase (PER) and oxalate O-hydroxycinnamyl transferase (HST) were upregulated after HCRV and TSWV infection. When HCRV infected peppers, acetyl-CoA-benzyl alcohol acetyltransferase (BEAT), cinnamyl alcohol dehydrogenase (CAD), peroxidase (PER), oxalate O-hydroxycinnamyl transferase (HST), and CYP73A were all upregulated, increasing the accumulation of lignin, which is beneficial to the defence response of plants (Fig. 4C).

\section{Changes in transcription factor expression in the plant defence response}


Transcription regulation is an important mechanism of eukaryotic gene expression and plays an important role in plant defence responses. Transcription factor family (TF) analysis of DEG in 12 cDNA libraries showed that there were $2350 \mathrm{DEG}$ distributed in 52 transcription factor families, of which $\mathrm{C} 3 \mathrm{H}$ (674), bHLH (142), MYB (130), C2H2 (111), ERF (109), MYB-related (103), NAC (77), and WRKY (72), among others, are related to plant defence response (Fig. 5).

Transcriptome data showed that compared with the control (CK), a total of 32 TFs were expressed after HCRV treatment, including 17 upregulated and 15 downregulated TFs. These TFs are divided into 16 different families, mainly C3H, MYB, ARR-B, ERF, LBD, HD-ZIP, bHLH and MYB-related (Fig. 6A). Among them, the upregulated TF families mainly included MYB (12.5\%), C3H (9.4\%), ARR-B (6.3\%), bHLH (6.3\%) and MYB-related (6.3\%), and the downregulated TFs mainly included ERF (9.4\%), C3H (6.3\%), ARR-B (6.3\%) and LBD (6.3\%).

Compared with the control (CK), 33 TFs were differentially expressed after TSWV treatment, including 20 upregulated and 13 downregulated TFs. These TFs are divided into 21 different families, mainly ERF, HDZIP, MYB-related, bHLH, CO-like, WRKY, ARR-B, and AP2 (Fig. 6B). Among them, the upregulated TF families mainly included MYB-related (6.1\%), bHLH (6.1\%), CO-like (6.1\%), and HD-ZIP (6.1\%), and the downregulated TF families mainly included ERF (9.1\%), ARR-B (6.1\%), and LBD (6.1\%). Many of these TF are involved in the response to plant defence and signal pathways activated by JA. Therefore, we focused on the transcription factors WRKY, MYB, AP2/ERF and other reactions to plant defence.

We analysed the TFs in the CK-vs-H and CK-vs-T comparison groups. The results showed that TFs such as $\mathrm{C} 3 \mathrm{H}, \mathrm{MYB}$, and ARR-B in the CK-vs-H comparison group were upregulated, but WRKY, ERF and LBD TFs were downregulated (Fig. 6A); in the CK-vs-T comparison group, MYB, MYB_related, bHLH, bZIP and other TFs were upregulated, and ERF, WRKY and other TFs were downregulated (Fig. 6B).

\section{qRT-PCR experiment results}

To further confirm the gene expression pattern of the differentially expressed transcripts identified by RNA-Seq, we selected 10 annotated unigenes for qRT-PCR experiments (Fig. 7). These candidate genes are closely related to the transcription factor family and hormone and phenylpropanoid synthesis. The results showed that the 10 gene expression profiles obtained by qRT-PCR had high similarities with RNASeq data. These findings confirm the reliability of the differential expression analysis data obtained by RNA-Seq and reflect the actual transcriptomic changes in the defence response of peppers after virus infection.

\section{Discussion}

Symptoms and transcriptome levels changed after infection of pepper with the two kinds of orthotospoviruses. At $7 \mathrm{dpi}$, TSWV-infested peppers showed leaf chlorosis and yellowing, followed by leaf deformities and concentric rings. After HCRV friction inoculation of pepper, local cell necrosis appeared on the inoculated leaves. As the plants grew, the new leaves on the upper parts of the inoculated leaves grew normally, and molecular testing revealed that there was no virus present. The resistance difference 
between TSWV and HCRV after infecting peppers may be related to the molecular structures of the viruses, the transport efficiency of virus particles in plants, the differences in avirulent (Avr) recognized by NLRs (nucleotide-binding leucine-rich repeat receptors), the different strains (TSWV is the American strain, HCRV is the Eurasian strain) and the types of resistance genes in peppers.

The results of comparative transcriptomics studies on peppers infected by TSWV and HCRV showed that a large number of hub genes were upregulated in hormone signal transduction, plant-pathogen interaction and secondary metabolic pathways after the plants were infected with the two viruses. Previous researchers conducted a comparative transcriptome study after orthotospovirus TZSV was used to infect tobacco, and the KEGG pathway analysis of DEG after infection mainly consisted of multiple processes, such as primary and secondary metabolism, photosynthesis, and plant-pathogen interactions[13]. The results of this study are essentially similar to the results of TZSV alone infecting tobacco, but the difference is that the DEG enrichment pathway in this study includes plant hormone signal transduction. The key JA synthesis genes JAZ (TIFY10A and MYC2) in the plant hormone signal transduction pathway were significantly upregulated, which ultimately promoted the synthesis of JA. The upregulated expression of $\mathrm{JA}$ is conducive to the synthesis of primary and secondary metabolites, such as nicotine and terpene indole alkaloids (TIAs), anthocyanins, artemisinin and other metabolites; as a result, the increase in JA expression is conducive to the disease resistance of plants[33-36]. In addition, studies have found that the nonstructural protein NSs of TSWV inhibits plant MYC-regulated JA signal transduction and enhances its attractiveness to vectors[37]. The main purpose of this study was to analyse the DEG in pepper following infection with the two viruses; the transmission vector of the virus was not studied. The interaction between the host and the virus can be evaluated in a follow-up study.

Plant transcription factors play an important role in the defence process of plants. Research results show that the expression levels of transcription factors such as WRKY, MYB, ERF, and MYC (BHLH) are changed after plants are infected by viruses, and these transcription factors participate in the signal transduction of plant hormones, plant-pathogen interactions, the synthesis of secondary metabolites and other pathways and, ultimately, enhance the defence capabilities of host plants [21, 24,38-43]. The results of this research show that WRKY, MYB, ERF and other TFs underwent major changes compared with the CK after virus inoculation, which is similar to the results of a previous single orthotospovirus infection study.

Orthotospoviruses can complete their own life activities with the help of their host. Plants have evolved two layers of defence mechanisms to prevent their invasion. One is the activation of the antiviral RNA interference (RNAi) defence response, and the other is the recognition of different virus effectors (such as NSs and NSm) through their own cellular innate immune receptors (such as $T s w$ and $S w-5 b$ ) [2, 44]. In the process of pathogen invasion, plant NLRs recognize specific pathogen effectors and trigger so-called effector-triggered immunity (ETI). The defence response triggered by $T s w$ and $S w-5 b$ disease resistance genes belongs to the ETI type[45, 46]. Previous research has found that the CaHsp25.9 gene has a positive regulatory effect on the tolerance of peppers to heat, salt and drought stress[47]. In addition, previous researchers have shown that $H s p 70$ can improve the heat resistance of peppers[48]. This research found that after TSWV and HCRV infect plants, heat shock protein (HSP90) and resistance 
protein (RPS2) are the hub genes in the ETI pathway in the plant-pathogen interaction pathway. Previous researchers found that SGT1-HSP90 (small glutamine-rich tetratricopeptide repeat-containing protein, SGT1) and the antagonistic genes Rx, RPM1, Mla, N, Prf, Mi, I2, R3a, Lr21 and RPS2 mediated close relationships in plant disease resistance, indicating that $R$ gene-mediated resistance depends on HSP90[49]. Whether there is a mutual dependence between HSP90 and the resistance gene Tsw in pepper remains to be further researched.

The response intensity of Xiangyan 11 in the plant-pathogen interaction pathway after HCRV inoculation was greater than those of TSWV, CDPK, CALM, HSP90, RPS2, and $\angle R R$ receptor protein kinases. During the defence process of PAMP-triggered immunity (PTI), the calcium ion concentration rapidly flows into the cell wall, which eventually leads to the upregulation of CALM and CDPK. In the process of ETI immunization, the heat shock protein $H S P 90$ is upregulated, which is conducive to the formation of the HR response[50]. The predecessors were resistant to two different kinds of Solanaceae plants (Petunia hybrida is resistant to TSWV, while TSWV can infect Nicotiana tabacum systemically). In the analysis of the specific and shared defence mechanisms triggered by the TSWV virus inoculation, research results show that the defence mechanisms based on reactive oxygen species (ROS) are both present in two species of Solanaceae with different resistance[51]. The results of our research did not show that the expression of ROS was upregulated. We found that the hub genes CPK and CALM were upregulated during the process of ROS synthesis. The reason for this phenomenon may be that the synthesis of ROS has not been completed at the initial stage of virus infection.

The results of this study showed that the number of differential genes induced by the two viruses inoculated with Orthotospovirus was significantly different after the viruses infected peppers, and significantly more genes were differentially induced by HCRV infection than by TSWV infection. We analysed the metabolic pathways of DEG after virus inoculation. The analysis results showed that HCRV and TSWV were significantly enriched in the pathways of plant-pathogen interaction, plant hormone signal transduction, and phenylpropanoid synthesis after inoculation. The hub genes of the plant were significantly upregulated, ultimately enhancing plant resistance. In addition, we focused on the TFs of pepper. WRKY, MYB, and AP2/ERF, among others, underwent major changes relative to the CK. Therefore, we infer that after HCRV and TSWV infect plants, DEG undergo major changes in the processes of plantpathogen interaction, hormone signal transduction and secondary metabolites and changes in plant TF families, such as WRKY, MYB, and ERF. The selected candidate genes related to plant defence were verified by qRT-PCR, and it was found that the qRT-PCR experiment and the RNA-Seq sequencing results correlated well, demonstrating that the RNA-Seq sequencing results were correct and reliable. Gene overexpression and gene knockout experiments on the selected 10 candidate genes should be conducted in a follow-up study to further verify whether the candidate genes play defensive roles in plant defence responses. Through overexpression, gene knockout or gene editing of these candidate genes, the disease resistance of plants is ultimately enhanced, which can be applied to the disease resistance breeding of peppers and other plants. 


\section{Conclusion}

High-throughput RNA-Seq analysis was used in this study, which allowed us to draw some rules between TSWV, HCRV infection and changes in gene expression in infected peppers. The GO and KEGG pathway enrichment analysis revealed the affected defense response in host plants infected by TSWV and HCRV, and showed how mock- and TSWV-inoculation, HCRV-inoculation triggers different metabolic processes. Our research further analyzes the systemic level changes related to TSWV and HCRV infection, and provides a reference for future exploration of TSWV and HCRV disease resistance breeding.

\section{Abbreviations}

dpi, day after inoculation ; GO, Gene Ontology; KEGG, Kyoto Encyclopedia of Genes and Genomes; JA, jasmonic acid; SA, salicylic acid; RIN, RNA intact value; DEG, differentially expressed genes; qRT-PCR, quantitative real-time polymerase chain reaction; FPKM, fragment kilobase of exon model per million mapped reads; TF, transcription factor; ANOVA, analysis of variance; CDPK, calcium-dependent protein kinase; HSP90, heat shock protein; HR, hypersensitive response; ABA, abscisic acid; ETH, ethylene; COMT, caffeic acid methyltransferase; PER, peroxidase; HST, O-hydroxycinnamyl transferase; BEAT, acetyl-CoAbenzyl alcohol acetyltransferas; CAD, cinnamyl alcohol dehydrogenase; HST, oxalate 0-hydroxycinnamyl transferase; CYP73A, anti-cinnamic acid 4-monooxygenase; RNAi, RNA interference; ETI, effector-triggered immunity; PTI, PAMP-triggered immunity; HSP, heat shock protein; RPS, resistance protein; SGT, small glutamine-rich tetratricopeptide repeat-containing protein; ROS, reactive oxygen species

\section{Declarations}

\section{Acknowledgements}

Authors are thankful to plant virology lab members for their support in conducting the experiments.

\section{Funding}

This work was supported by the National Science Foundation of China (No.31471828 \& 31260451) and a Project on Applied Basic Research Foundation of Yunnan Province (2018FA019).

\section{Availability of data and materials}

All data generated or analysed during this study are included in this published article and its Additional files $1,2,3,4,5$ and 6 .

\section{Authors contributions}

Yating Liu, Yongzhong Li and Zhiqiang Jia conceived and designed the experiments. Xue Gao, Ye Xu, Hongzheng Tao, Baoju Yang and Min Gui performed the experiments and the statistical analysis. Zhiqiang Jia wrote and finalized the manuscript. All authors read and approved the final manuscript. 


\section{Ethics approval and consent to participate}

Not applicable.

\section{Consent for publication}

Not applicable.

\section{Competing interests}

The authors declare that they have no competing interests.

\section{References}

1. Pohronezny K: Compendium of pepper diseases. St. Paul, Minn., USA: American Phytopathological Society; 2003.

2. Zhu M, van Grinsven IL, Kormelink R, Tao XR: Paving the Way to Tospovirus Infection: Multilined Interplays with Plant Innate Immunity. Annual Review of Phytopathology, Vol 57, 2019 2019, 57:4162.

3. Zhao K, Rosa C: Thrips as the Transmission Bottleneck for Mixed Infection of Two Orthotospoviruses. Plants 2020, 9:509.

4. Kuo YW, Gilbertson RL, Turini T, Brennan EB, Smith RF, Koike ST: Characterization and Epidemiology of Outbreaks of Impatiens necrotic spot virus on Lettuce in Coastal California. Plant Dis 2014, 98:1050-1059.

5. Sharma A, Kulshrestha S: Molecular characterization of tospoviruses associated with ringspot disease in bell pepper from different districts of Himachal Pradesh. Virusdisease 2016, 27:188-192.

6. Almeida MMS, Orilio AF, Melo FL, Rodriguez R, Feliz A, Cayetano X, Martinez RT, Resende RO: The First Report of Tomato chlorotic spot virus (TCSV) Infecting Long Beans and Chili Peppers in the Dominican Republic. Plant Dis 2014, 98:1285.

7. McMichael LA, Persley DM, Thomas JE: A new tospovirus serogroup IV species infecting capsicum and tomato in Queensland, Australia. Australasian Plant Pathology 2002, 31:231-239.

8. Olaya C, Velasquez N, Betancourt Vásquez M, Cuellar W, Pappu H: First Report of natural infection of tomato (Solanum lycopersicum L.) and bell pepper (Capsicum annuum) by Alstroemeria necrotic streak virus in Colombia. Plant Disease 2017, 101.

9. Zheng K, Chen TC, Wu K, Kang YC, Yeh SD, Zhang Z, Dong J: Characterization of a New Orthotospovirus from Chilli Pepper in Yunnan Province, China. Plant Dis 2020, 104:1175-1182.

10. Kenyon L, Kumar S, Tsai WS, Hughes JD: Virus Diseases of Peppers (Capsicum spp.) and Their Control. Control of Plant Virus Diseases-Seed-Propagated Crops 2014, 90:297-354.

11. Senthil G, Liu H, Puram VG, Clark A, Stromberg A, Goodin MM: Specific and common changes in Nicotiana benthamiana gene expression in response to infection by enveloped viruses. J Gen Virol 
2005, 86:2615-2625.

12. Choi H, Jo Y, Lian S, Jo KM, Chu H, Yoon JY, Choi SK, Kim KH, Cho WK: Comparative analysis of chrysanthemum transcriptome in response to three RNA viruses: Cucumber mosaic virus, Tomato spotted wilt virus and Potato virus X. Plant Mol Biol 2015, 88:233-248.

13. Huang C, Cun Y, Yu H, Tong Z, Xiao B, Song Z, Wang B, Li Y, Liu Y: Transcriptomic profile of tobacco in response to Tomato zonate spot orthotospovirus infection. Virol J 2017, 14:153.

14. Zheng X, Chen Y, Zhao L, Chen Y, Zheng L, Zheng K, Mu Y, Zhao X, Gao Y, Zhang J: Tripartite interactions between jasmonic/salicylic acid pathways, western flower thrips, and thrips-transmitted tomato zonate spot virus infection in Capsicuum annuum. Arthropod-Plant Interactions 2019, 13:289-297.

15. Pappu HR, Jones RA, Jain RK: Global status of tospovirus epidemics in diverse cropping systems: successes achieved and challenges ahead. Virus Res 2009, 141:219-236.

16. Zhao L, Hu Z, Li S, Zhou X, Li J, Su X, Zhang L, Zhang Z, Dong J: Diterpenoid compounds from Wedelia trilobata induce resistance to Tomato spotted wilt virus via the JA signal pathway in tobacco plants. Sci Rep 2019, 9:2763.

17. Padmanabhan C, Ma QY, Shekasteband R, Stewart KS, Hutton SF, Scott JW, Fei ZJ, Ling KS: Comprehensive transcriptome analysis and functional characterization of $P R-5$ for its involvement in tomato $S w-7$ resistance to tomato spotted wilt tospovirus. Scientific Reports 2019, 9.

18. Xu M, Chen J, Huang Y, Shen D, Sun P, Xu Y, Tao X: Dynamic Transcriptional Profiles of Arabidopsis thaliana Infected by Tomato spotted wilt virus. Phytopathology 2020, 110:153-163.

19. Oh SK, Baek KH, Park JM, Yi SY, Yu SH, Kamoun S, Choi D: Capsicum annuum WRKY protein CaWRKY1 is a negative regulator of pathogen defense. New Phytol 2008, 177:977-989.

20. Pandey SP, Somssich IE: The role of WRKY transcription factors in plant immunity. Plant Physiol 2009, 150:1648-1655.

21. Rushton PJ, Somssich IE, Ringler P, Shen QJ: WRKY transcription factors. Trends Plant Sci 2010, 15:247-258.

22. Jingyuan Z, Xuexiao Z, Zhenchuan M, Bingyan X: A novel pepper (Capsicum annuum L.) WRKY gene, CaWRKY30, is involved in pathogen stress responses. Journal of Plant Biology 2011, 54:329.

23. Dang F, Wang Y, She J, Lei Y, Liu Z, Eulgem T, Lai Y, Lin J, Yu L, Lei D, et al: Overexpression of CaWRKY27, a subgroup Ile WRKY transcription factor of Capsicum annuum, positively regulates tobacco resistance to Ralstonia solanacearum infection. Physiol Plant 2014, 150:397-411.

24. Diao WP, Snyder JC, Wang SB, Liu JB, Pan BG, Guo GJ, Wei G: Genome-Wide Identification and Expression Analysis of WRKY Gene Family in Capsicum annuum L. Front Plant Sci 2016, 7:211.

25. Ashraf MF, Yang S, Wu R, Wang Y, Hussain A, Noman A, Khan MI, Liu Z, Qiu A, Guan D, He S: Capsicum annuum HsfB2a Positively Regulates the Response to Ralstonia solanacearum Infection or High Temperature and High Humidity Forming Transcriptional Cascade with CaWRKY 6 and CaWRKY40. Plant Cell Physiol 2018, 59:2608-2623. 
26. Wan H, Yuan W, Ruan M, Ye Q, Wang R, Li Z, Zhou G, Yao Z, Zhao J, Liu S, Yang Y: Identification of reference genes for reverse transcription quantitative real-time PCR normalization in pepper (Capsicum annuum L.). Biochem Biophys Res Commun 2011, 416:24-30.

27. Livak KJ, Schmittgen TD: Analysis of relative gene expression data using real-time quantitative PCR and the 2(-Delta Delta C(T)) Method. Methods 2001, 25:402-408.

28. Anders S, Pyl PT, Huber W: HTSeq-a Python framework to work with high-throughput sequencing data. Bioinformatics 2015, 31:166-169.

29. Trapnell C, Williams BA, Pertea G, Mortazavi A, Kwan G, van Baren MJ, Salzberg SL, Wold BJ, Pachter L: Transcript assembly and quantification by RNA-Seq reveals unannotated transcripts and isoform switching during cell differentiation. Nat Biotechnol 2010, 28:511-515.

30. Young MD, Wakefield MJ, Smyth GK, Oshlack A: Gene ontology analysis for RNA-seq: accounting for selection bias. Genome Biol 2010, 11:R14.

31. Mao XZ, Cai T, Olyarchuk JG, Wei LP: Automated genome annotation and pathway identification using the KEGG Orthology (KO) as a controlled vocabulary. Bioinformatics 2005, 21:3787-3793.

32. Perez-Rodriguez P, Riano-Pachon DM, Correa LG, Rensing SA, Kersten B, Mueller-Roeber B: PInTFDB: updated content and new features of the plant transcription factor database. Nucleic Acids Res 2010, 38:D822-827.

33. Zhu F, Xi DH, Yuan S, Xu F, Zhang DW, Lin HH: Salicylic acid and jasmonic acid are essential for systemic resistance against tobacco mosaic virus in Nicotiana benthamiana. Mol Plant Microbe Interact 2014, 27:567-577.

34. Alazem M, Lin NS: Roles of plant hormones in the regulation of host-virus interactions. Mol Plant Pathol 2015, 16:529-540.

35. Patkar RN, Naqvi NI: Fungal manipulation of hormone-regulated plant defense. PLoS Pathog 2017, 13:e1006334.

36. Wasternack C, Strnad M: Jasmonates are signals in the biosynthesis of secondary metabolites Pathways, transcription factors and applied aspects - A brief review. N Biotechnol 2019, 48:1-11.

37. Wu X, Xu S, Zhao P, Zhang X, Yao X, Sun Y, Fang R, Ye J: The Orthotospovirus nonstructural protein NSs suppresses plant MYC-regulated jasmonate signaling leading to enhanced vector attraction and performance. PLoS Pathog 2019, 15:e1007897.

38. Jiang Y, Yu D: WRKY transcription factors: links between phytohormones and plant processes. Sci China Life Sci 2015, 58:501-502.

39. Amorim LLB, da Fonseca Dos Santos R, Neto JPB, Guida-Santos M, Crovella S, Benko-Iseppon AM: Transcription Factors Involved in Plant Resistance to Pathogens. Curr Protein Pept Sci 2017, 18:335351.

40. Mabuchi K, Maki H, Itaya T, Suzuki T, Nomoto M, Sakaoka S, Morikami A, Higashiyama T, Tada Y, Busch W, Tsukagoshi H: MYB30 links ROS signaling, root cell elongation, and plant immune responses. Proc Natl Acad Sci USA 2018, 115:E4710-E4719. 
41. Ng DW, Abeysinghe JK, Kamali M: Regulating the Regulators: The Control of Transcription Factors in Plant Defense Signaling. Int J Mol Sci 2018, 19.

42. Cao Y, Li K, Li Y, Zhao X, Wang L: MYB Transcription Factors as Regulators of Secondary Metabolism in Plants. Biology (Basel) 2020, 9.

43. Zhang Y, Bouwmeester HJ, Kappers IF: Combined transcriptome and metabolome analysis identifies defence responses in spider mite-infested pepper (Capsicum annuum). J Exp Bot 2020, 71:330-343.

44. Jones JD, Dangl JL: The plant immune system. Nature 2006, 444:323-329.

45. Caplan J, Padmanabhan M, Dinesh-Kumar SP: Plant NB-LRR immune receptors: from recognition to transcriptional reprogramming. Cell Host Microbe 2008, 3:126-135.

46. Jones JD, Vance RE, Dangl JL: Intracellular innate immune surveillance devices in plants and animals. Science 2016, 354.

47. Feng XH, Zhang HX, Ali M, Gai WX, Cheng GX, Yu QH, Yang SB, Li XX, Gong ZH: A small heat shock protein CaHsp25.9 positively regulates heat, salt, and drought stress tolerance in pepper (Capsicum annuum L.). Plant Physiol Biochem 2019, 142:151-162.

48. Guo M, Liu JH, Ma X, Zhai YF, Gong ZH, Lu MH: Genome-wide analysis of the Hsp70 family genes in pepper (Capsicum annuum L.) and functional identification of CaHsp70-2 involvement in heat stress. Plant Sci 2016, 252:246-256.

49. Shirasu K: The HSP90-SGT1 chaperone complex for NLR immune sensors. Annu Rev Plant Biol 2009, 60:139-164.

50. Dodds PN, Rathjen JP: Plant immunity: towards an integrated view of plant-pathogen interactions. Nat Rev Genet 2010, 11:539-548.

51. Quecini V, Lopes ML, Pacheco FTH, Ongarelli MDG: Tomato spotted wilt virus triggers specific and shared defense mechanisms in hypersensitive and susceptible Solanaceae hosts. Physiological \& Molecular Plant Pathology 2007, 70:0-197.

\section{Figures}


$\mathbf{a}$

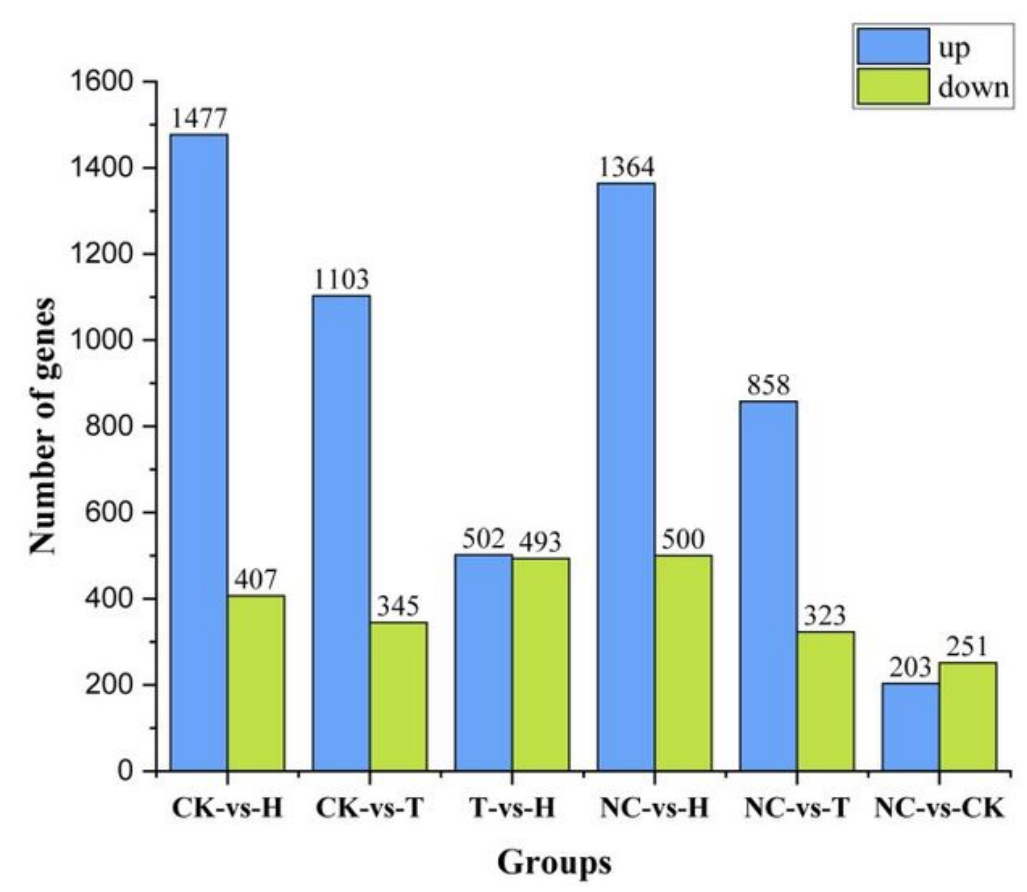

b

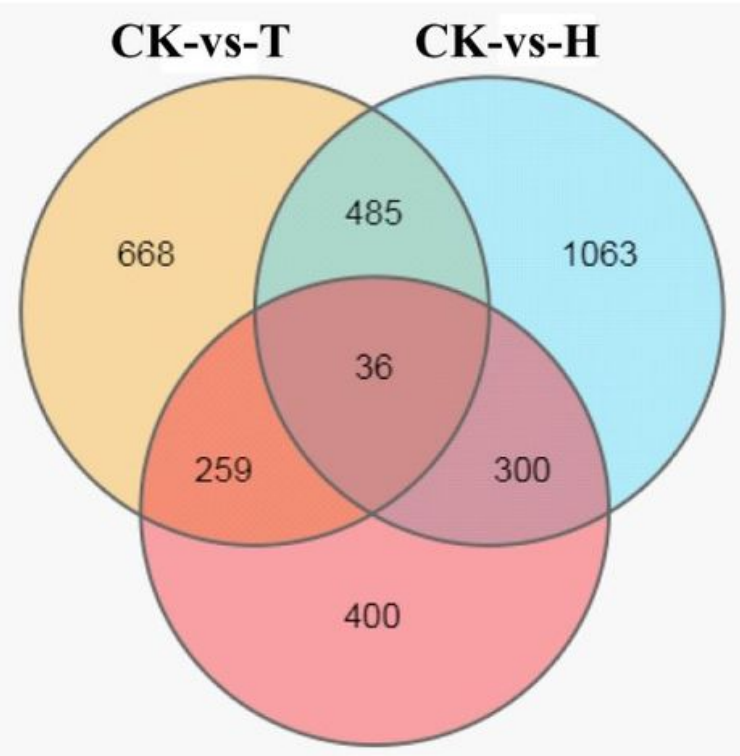

T-vs-H

Figure 1

DEG statistics of the comparison group. a. Statistics of DEG in comparison groups, b. The Venn diagram of DEG in the comparison group. 
a

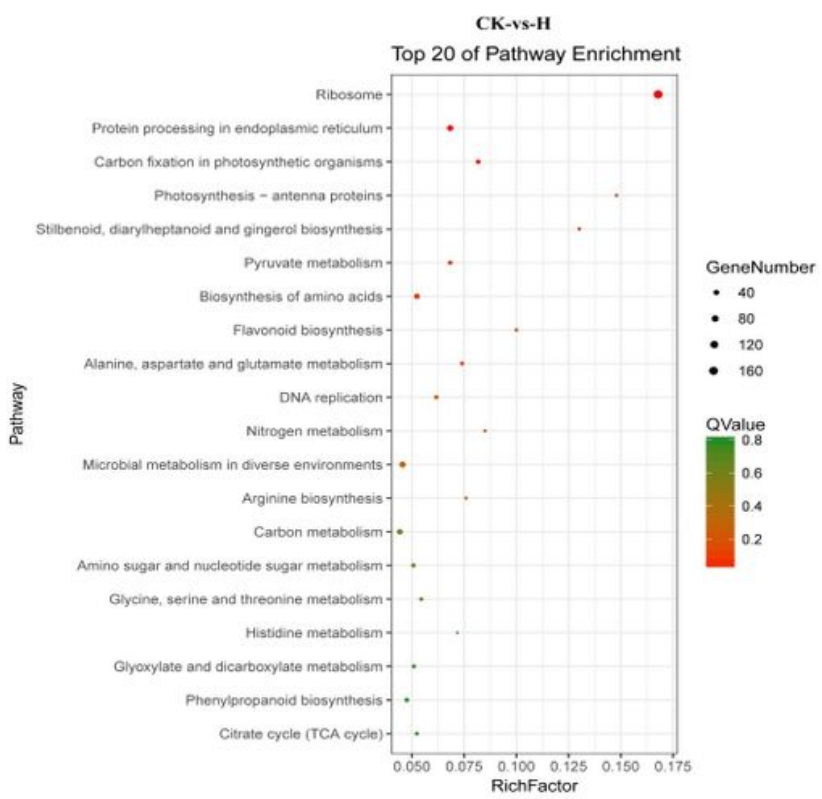

b

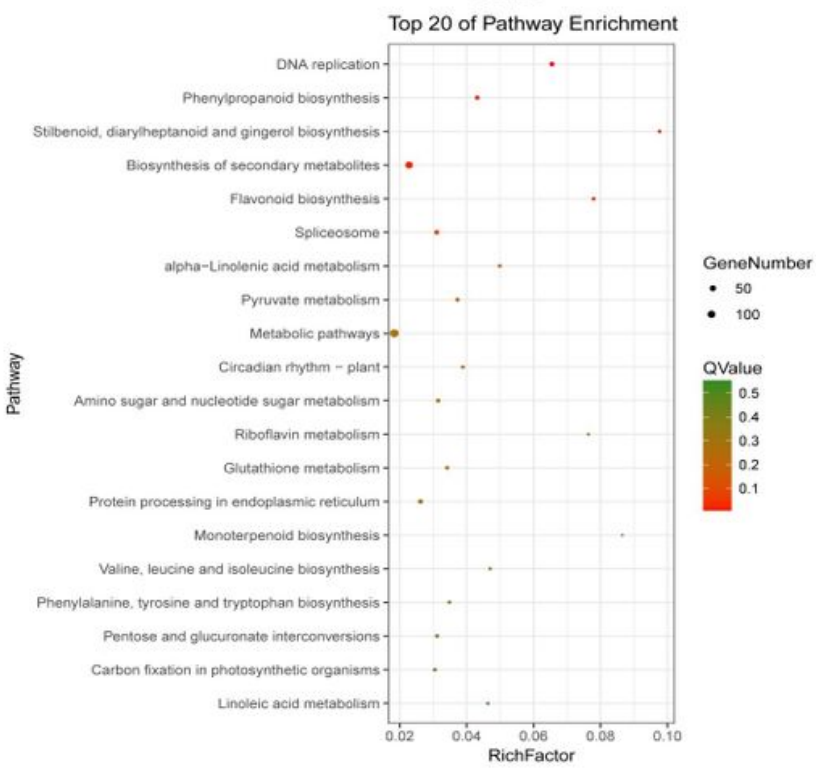

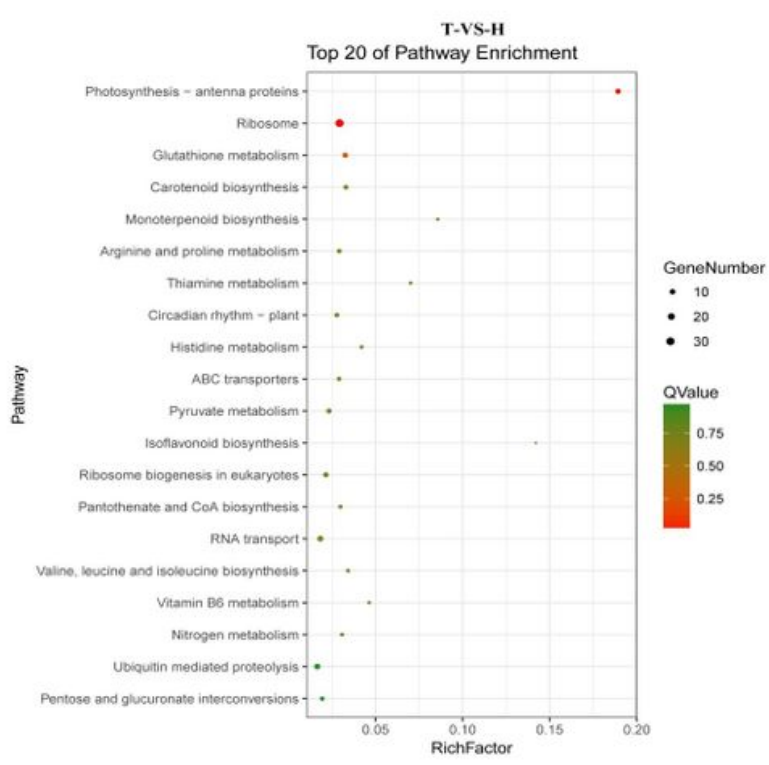

d

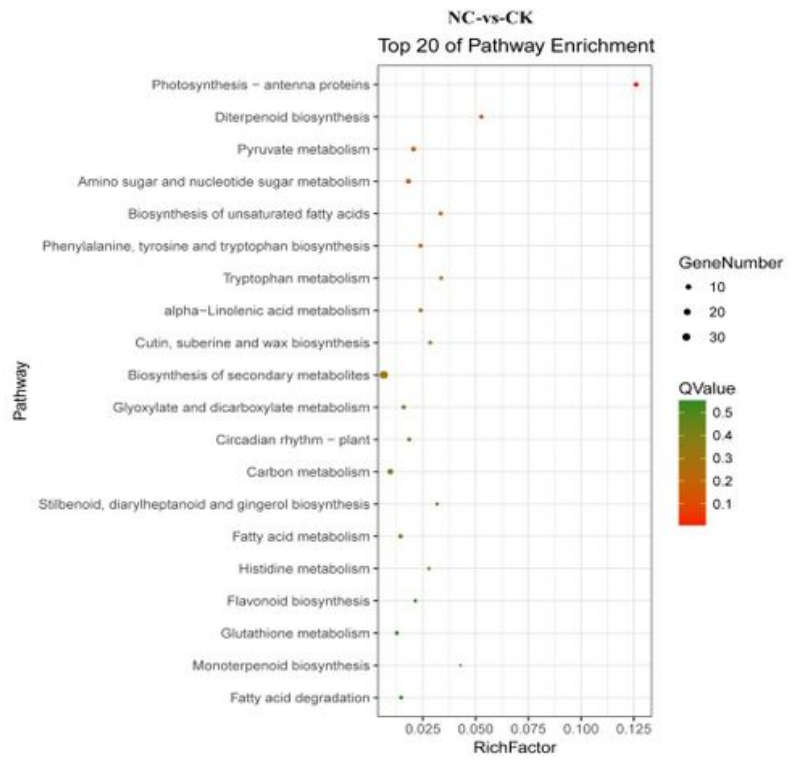

Figure 1

KEGG enrichment of 4 comparison groups. a. CK-vs-H comparison group, b. CK-vs-T comparison group, b. T-vs-H comparison group, d. NC-vs-CK comparison group. 


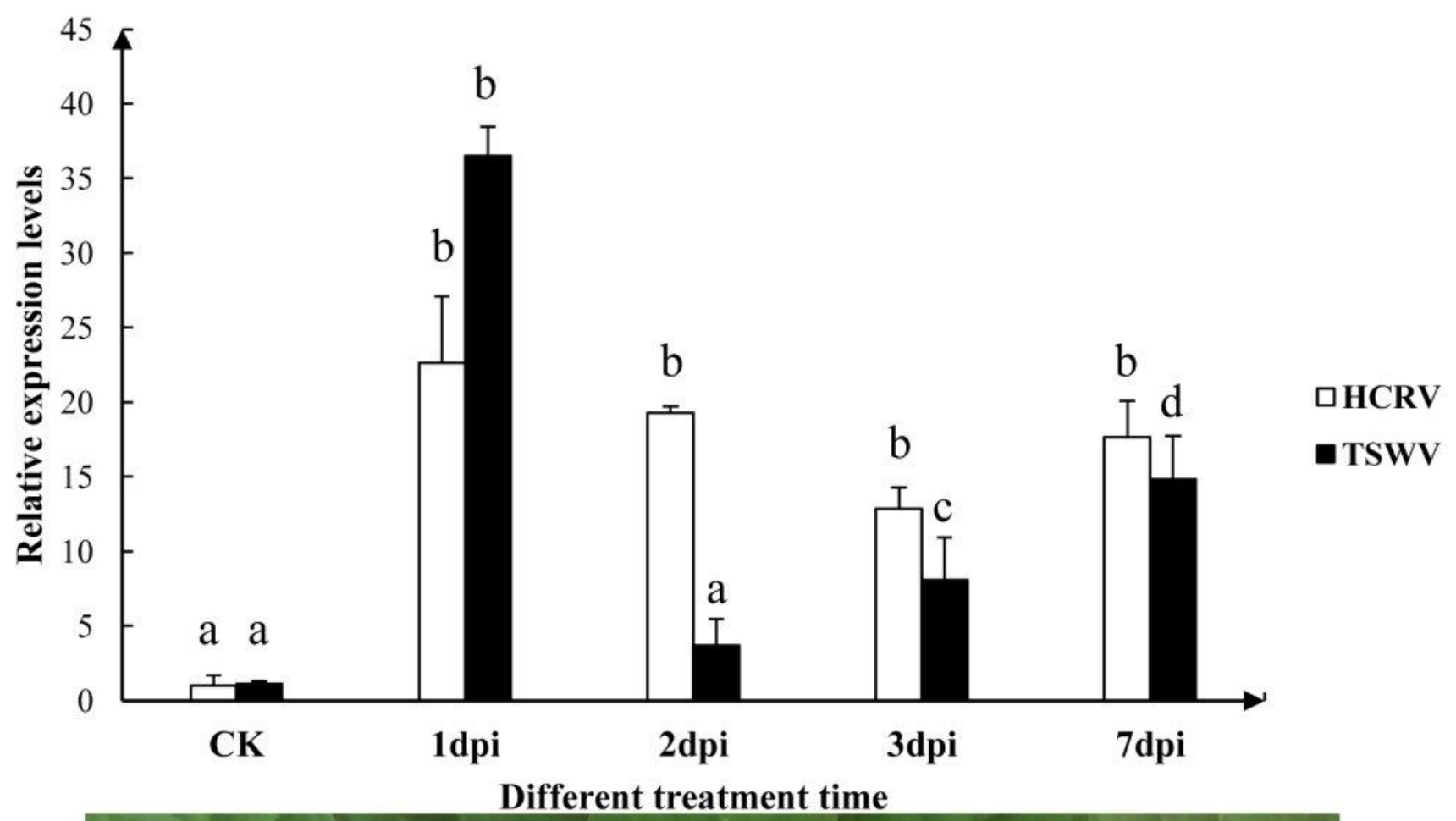

HCRV

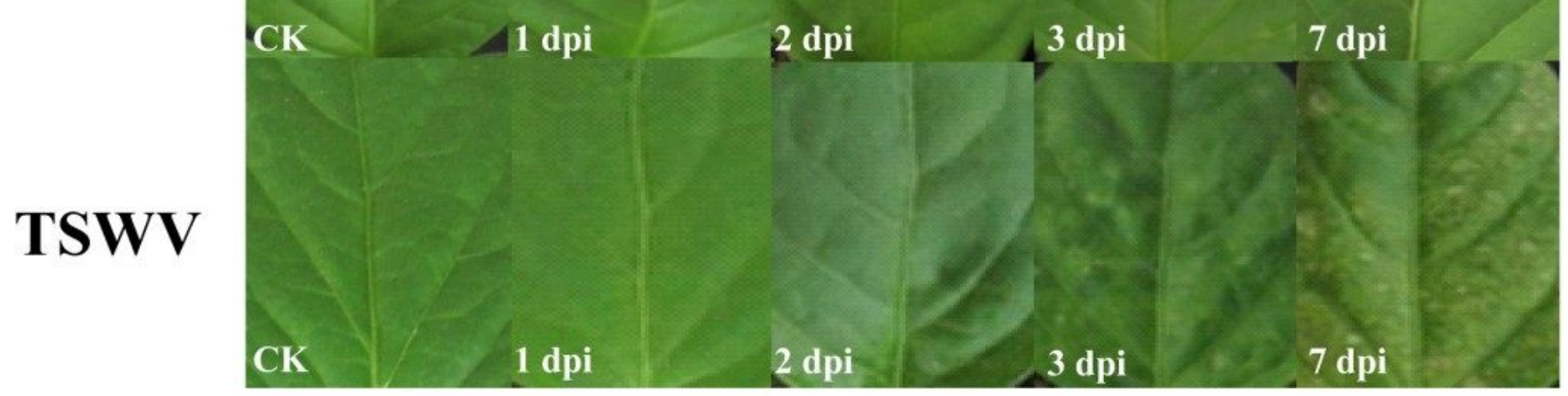

Figure 1

Accumulation after virus inoculation. CK indicates Xiangyan 11 vaccination buffer treatment, HCRV indicates inoculation with HCRV virus, and TSWV indicates inoculation with TSWV virus. 


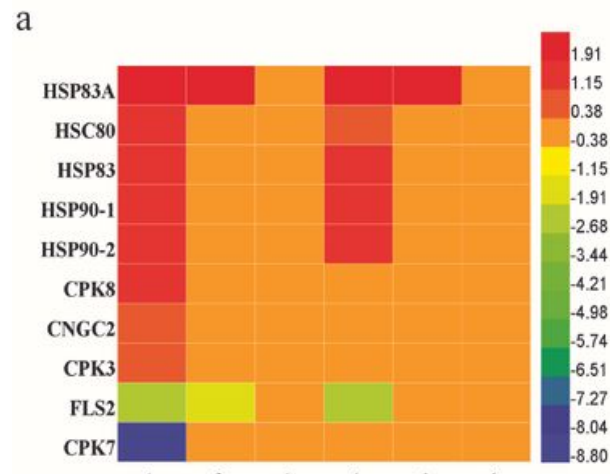

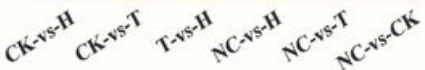

b

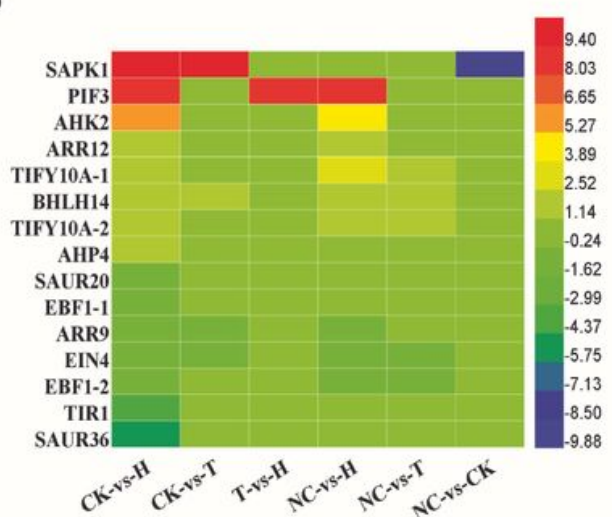

c

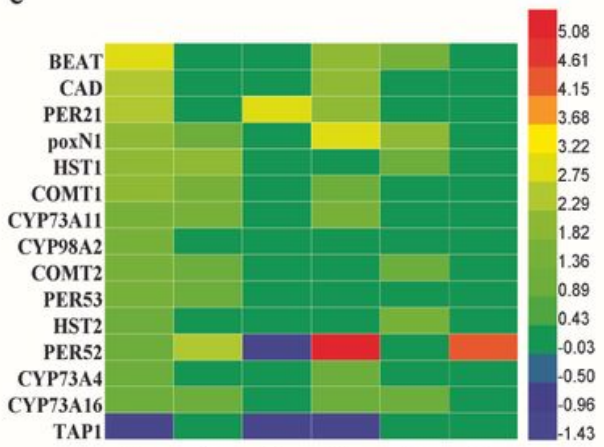

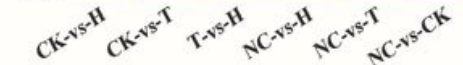

Figure 1

DEG involved in plant defence response. a. DEG participating in the plant-pathogen interaction pathway, b. DEG participating in the plant hormone signal transduction pathway, c. DEG participating in the phenylpropanoid biosynthetic pathway.

a

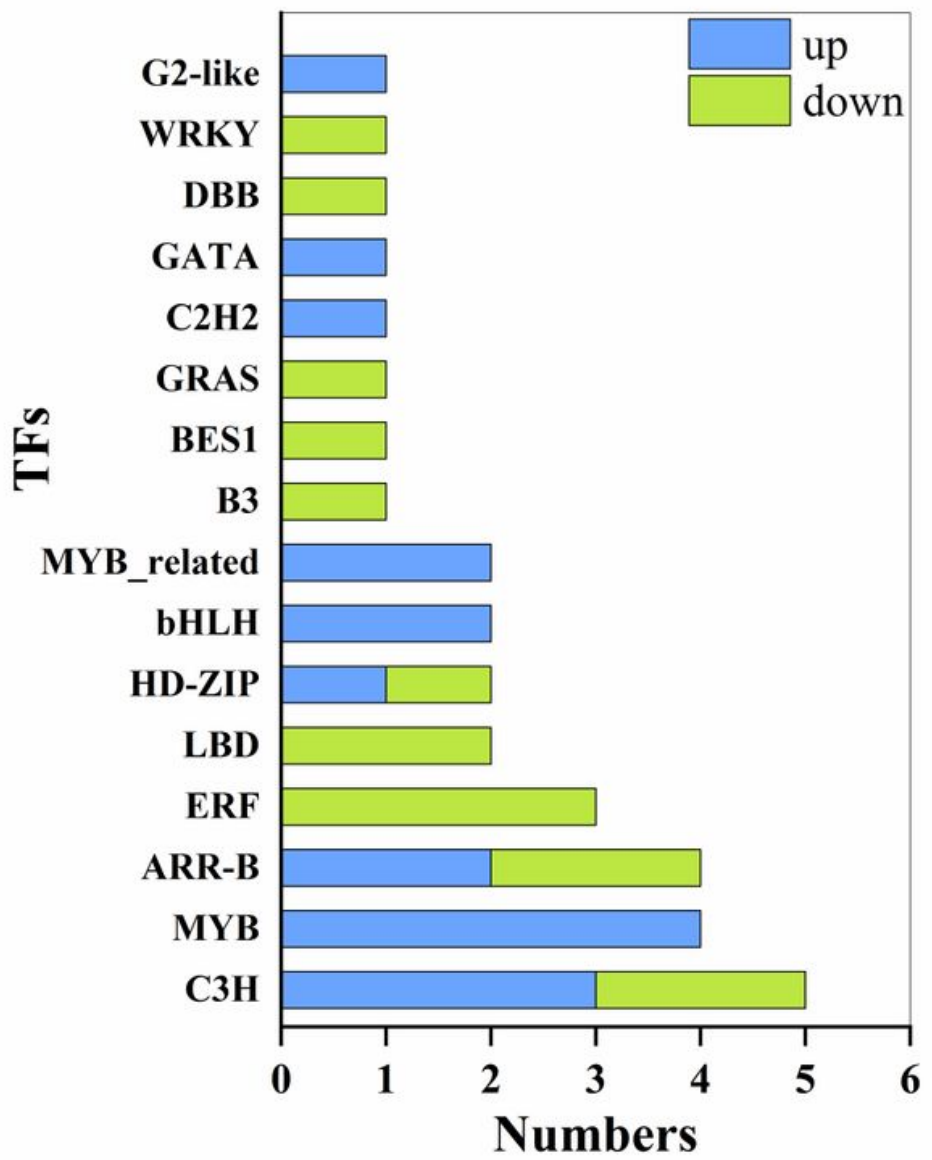

b

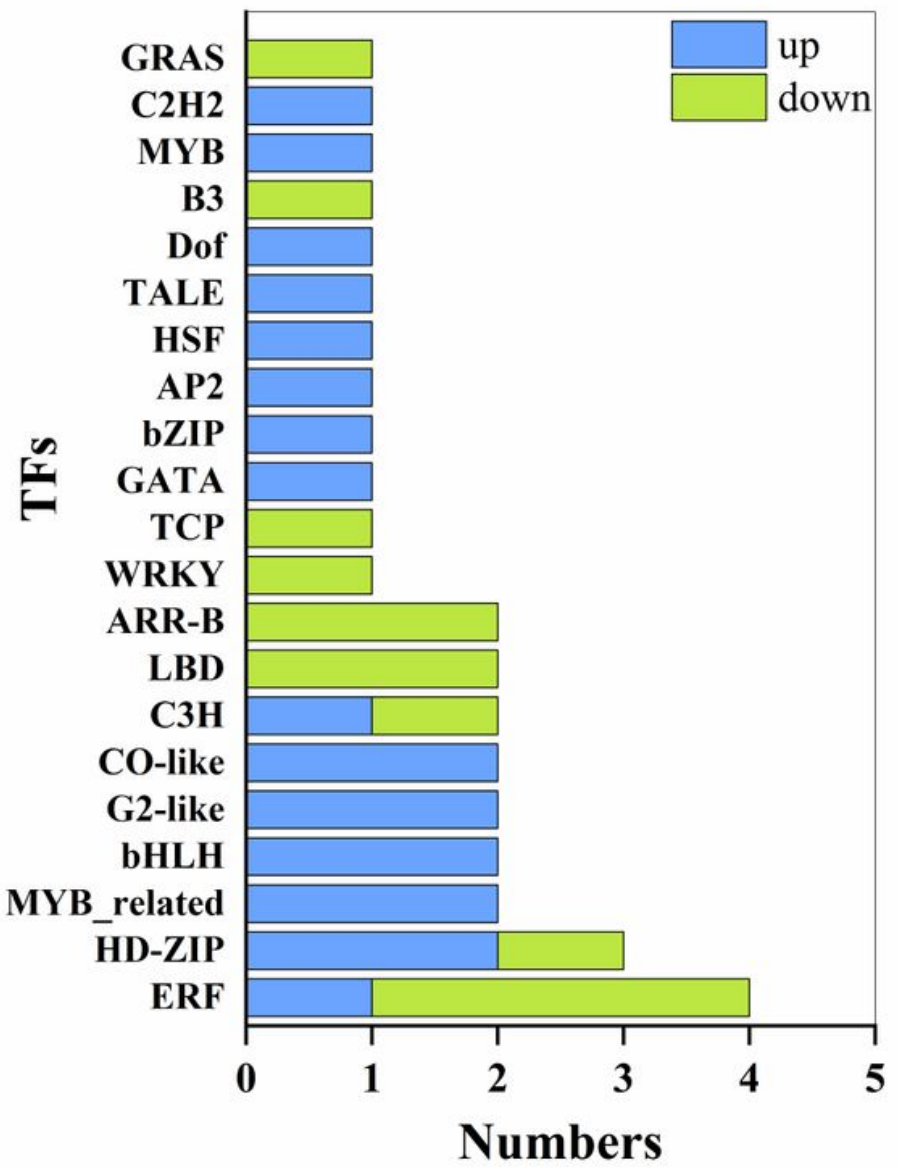

Figure 1 
Statistical analysis of the number of TF in the 2 comparison groups. a. CK-vs-H comparison group, b. CKvs-T comparison group

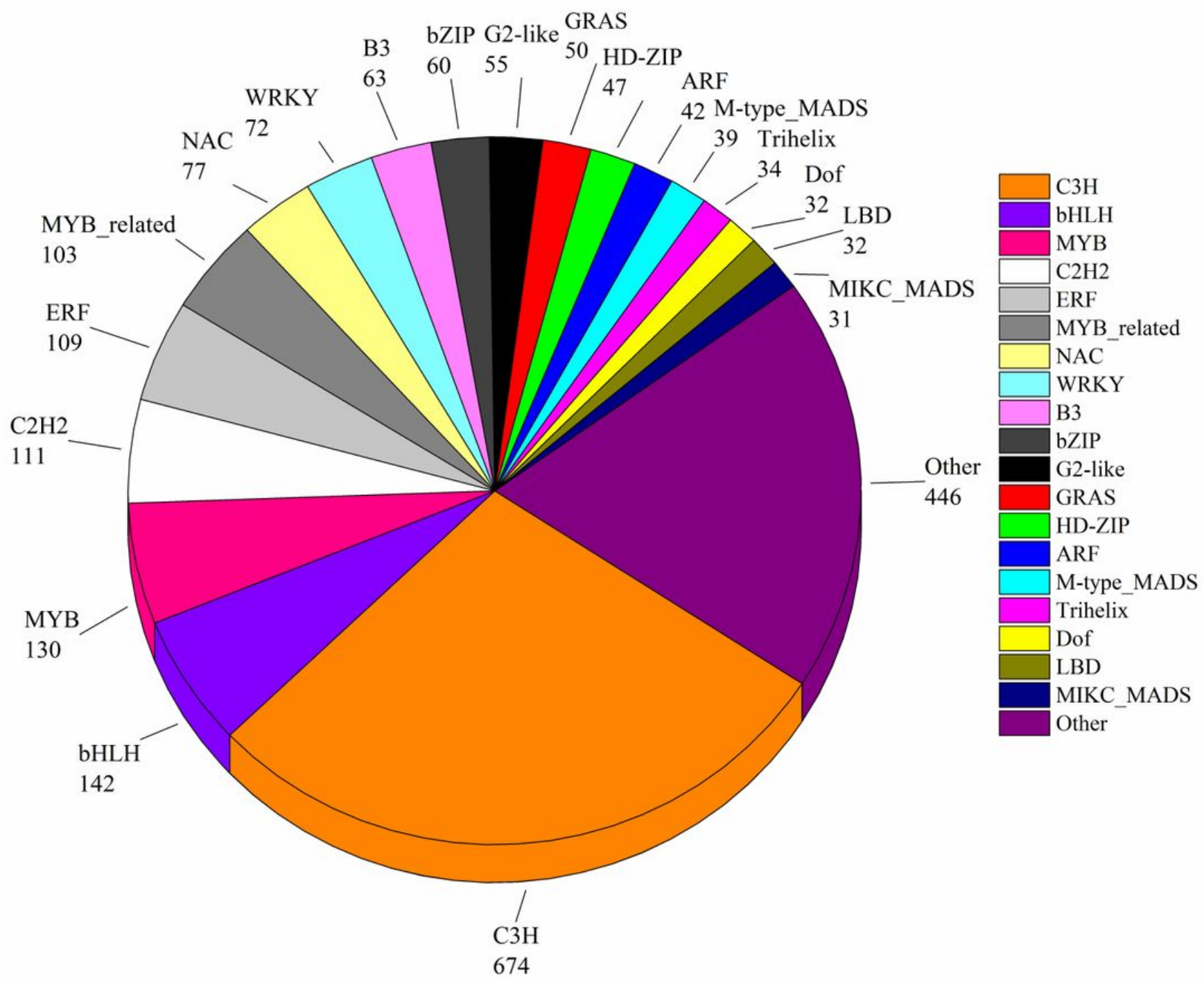

\section{Figure 1}

Statistical analysis of transcription factor families 

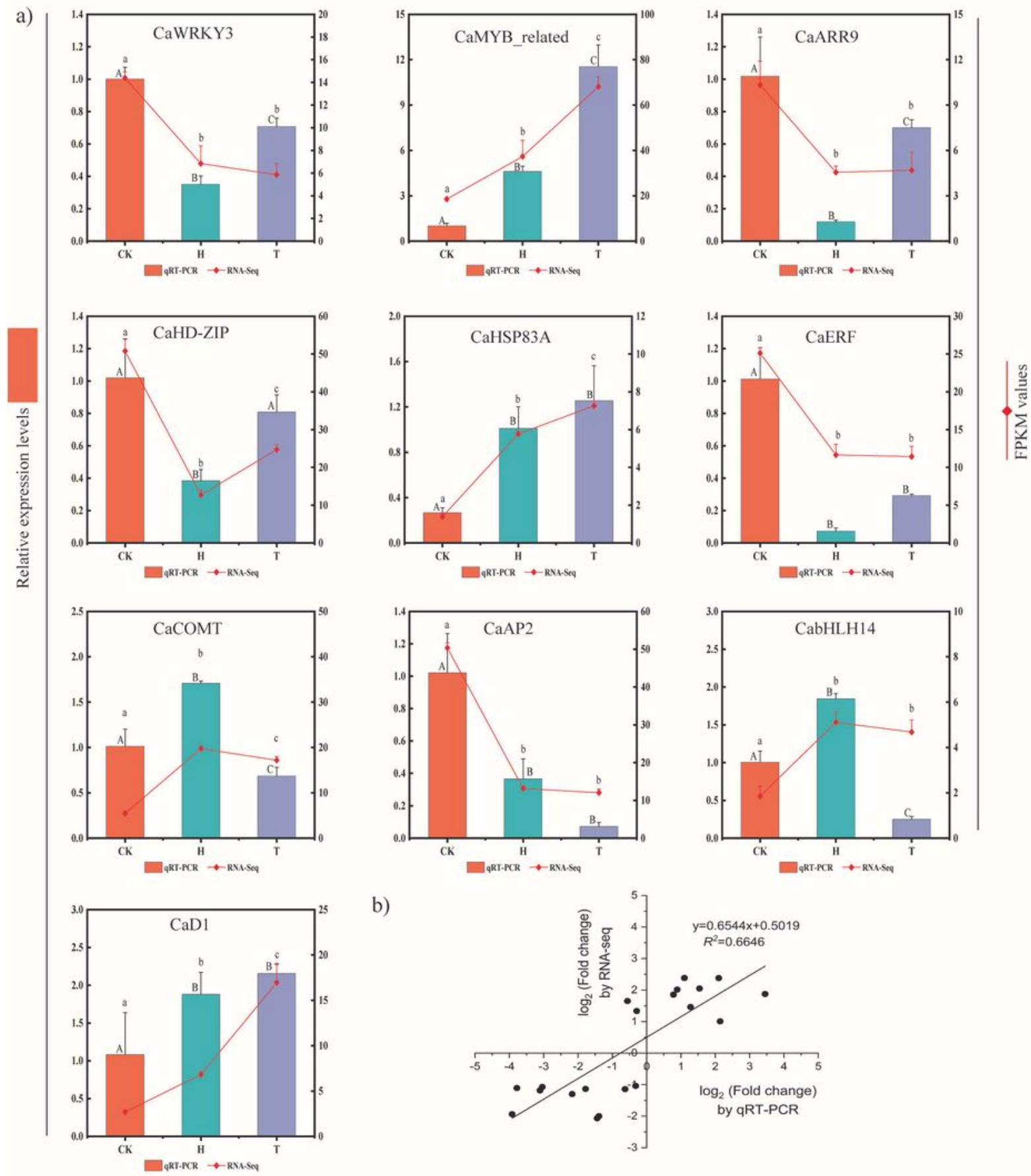

b)

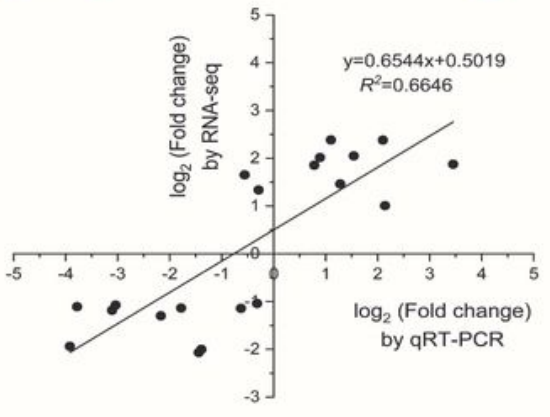

\section{Figure 1}

Expression levels of differentially expressed genes in the sample. a) qRT-PCR (column) and RNA-Seq (red line) revealed the transcription levels of 10 candidate DEG. qRT-PCR was used to verify the DEG identified by RNA-seq (Mean $\pm S E, n=2$ ). The data provided are the average of 3 replicates. Error bars indicate the standard deviation of each average. Different letters indicate significant differences $(p<0.05)$. The significance level of qRT-PCR is expressed in capital letters, and RNA-Seq is significant. The level is 
indicated by lowercase letters. 'CK' represents the transcriptome of inoculation buffer, 'H' represents the transcriptome of inoculation with HCRV virus, and 'T' represents the transcriptome of inoculation with TSWV virus. b) Analysis of the correlation levels of candidate DEG and qRT-PCR results.

\section{Supplementary Files}

This is a list of supplementary files associated with this preprint. Click to download.

- Tables4.doc

- TableS1.doc

- TableS5.doc

- Tables2.doc

- FigureS1.png

- Tables3.doc 